GUISCAFRÈ DANÚs, Jaume: Es jaquet d'en Jordi des Racó. Manacor: Institució Pública Antoni M. Alcover, 20I7, I57 p.

\title{
Es jaquet d'en Jordi des Racó
}

\author{
Roger Costa SOLÉ \\ Departament de Cultura. Generalitat de Catalunya
}

La reivindicació de la tasca dels folkloristes del segle xix és un exercici expiatori que algunes persones que ens hem format en l'antropologia estem realitzant d'un temps ençà, una mica amb la intenció de redimir l'actitud de les primeres generacions d'antropòlegs sorgides de l'acadèmia, les quals van fer mans i mànigues per diferenciar-se del folklore entès com una disciplina que veien acientífica i farcida de prejudicis ideològics. Amb els anys aquest capteniment —en part justificat, cal dir-ho- es va anar suavitzant i el distanciament es va anar escurçant, gràcies a l'obra d'autors com Llorenç Prats - la qual traspua una mena de relació d'amorodi cap als folkloristes de l'època clàssica-, Lluís Calvo ${ }^{\mathrm{I}}$ o Josefina Roma, ${ }^{2}$ per posar tres noms. Tal vegada no és el cas d'en Guiscafrè, que no ha renegat mai d'aquest passat, però en qualsevol cas crec que no és agosarat afirmar que la seva reivindicació fa part d'un procés més ampli de revisitació dels clàssics del folklore en llengua catalana, interessant i molt necessari, d'altra banda.

El llibre que ens ocupa és una compilació en un sol volum de tres articles del mateix autor sobre l'obra rondallística d'Antoni M. Alcover (de pseudònim Jordi des Racó) publicats amb anterioritat en revistes especialitzades, articles escrits des d'una admiració confessa de l'autor cap al personatge biografiat però que no resta rigor a l'anàlisi. En tractar-se de tres articles publicats en llocs i temps diferents, l'autor aborda diversos temes que en alguns casos es repeteixen, però que sovint van molt més enllà de la figura d'Antoni M. Alcover. Principalment: la genealogia de la rondallística a Catalunya (i, per tant, la prehistòria del nostre «patrimoni immaterial»), la personalitat i l'obra d'Antoni M. Alcover, així com aspectes tècnics sobre l'estudi i classificació de les rondalles, aspectes que no s'aborden aquí per se, sinó com a instrument per interpretar adequadament l'obra de l'ínclit folklorista mallorquí.

La munió de detalls que aporta Guiscafrè per justificar els seus arguments és reveladora de la cura amb què treballa. En aquest sentit, especialment interessant és la reinterpretació que fa de la genealogia dels estudis sobre rondallística en la nostra llengua. Així, mentre la cronologia bibliogràfica situa Milà i Fontanals com el primer compilador i estudiós de les rondalles catalanes amb les seves Observaciones sobre la poesia popular de I853, l'autor deixa clar que el primer compilador fou Marià Aguiló, que havia començat la seva tasca el I84I, i que el mateix Milà i

I Calvo ha escrit sobre etnòlegs com Tomàs Carreras i Artau o Ramon Violant i Simorra, però, per al tema que ens ocupa, el millor exemple segurament és la seva biografia de Joan Amades dins l'obra El món de Joan Amades. Barcelona: Generalitat de Catalunya, I990, p. II2-I9I.

2 A la seva trajectòria, farcida de referències d'aquesta mena, cal afegir-hi l'article «Aureli Capmany. Un dels gegants del Folklore a Catalunya», Aureli Capmany (I868-I954): Patufet on ets? Barcelona: Departament de Cultura, 2018, p. 2I-27.

Estudis de Literatura Oral Popular, núm. 7, 20I8, I77-I8I | DOI: Io.I7345/elop20I8I77-I8I ISSN: 2OI4-7996 | http://revistes.urv.cat/index.php/elop 
Fontanals així li ho reconeix el I882. Aquesta revelació 3 la fa en el marc del primer article, «Una bibliografia de les edicions i les traduccions de l'Aplec de Rondaies Mallorquines d'en Jordi des Racó», centrat en la història de l'obra publicada per Antoni M. Alcover.

A les pàgines I6-I7, l'autor fa una relació exhaustiva de revistes que van publicar rondalles d'Antoni Maria Alcover. Guiscafrè posa llum a la pauta —o manca de pauta, segons com es miri- general a què responia la publicació d'aquestes rondalles: els articles apareixien amb anterioritat, en paral-lel (a mode de publicitat) o posteriorment a la publicació de reculls, en revistes generalistes i en revistes especialitzades, on es publicaven contes la temàtica dels quals tenia a veure amb les temàtiques que tractaven. Les vint-i-set capçaleres periòdiques en què es publicaren aquests contes donen compte també de la seva popularitat i, si més no, de la presència del folklore en els mitjans de comunicació habituals a l'època. 4 «a difusió que varen tenir les rondalles per mitjà de revistes fou enorme», diu Guiscafrè. És de creure. En el text de Guiscafrè, a més, s'entreveuen dos aspectes que criden l'atenció: l'impacte que va tenir el recull i la publicació de rondalles entre la gent comuna, i el gran prestigi intel-lectual de què gaudia en aquells moments el folklore en el món occidental. Quant al primer, parafraseja Ernest Moliné, que, a la Revista Literària de I897, diu: «Ses Rondayes mallorquines, obra folklórica y literaria al mateix temps, están escrites molt garbosament, plenes á desdir de frases populars y paraules sols usades á Mallorca, per lo que no es estrany que en aquella Illa germana sian celebrades per la gent entesa y la profana». Quant al segon, Guiscafrè es fa ressò d'un carta enviada per Frederic Mistral, en què suggeria a Alcover que publiqués els seus contes a la Revue des Traditions Populaires, el director de la qual, Paul Sébillot, li proporcionava al seu torn contactes de diversos països d'Europa i dels Estats Units. El resultat foren dues ressenyes publicades en mitjans internacionals.

En aquest article també s'entreveu les polèmiques que va mantenir Alcover i l'Institut d'Estudis Catalans, així com la tasca que Francesc Borja Moll va realitzar per donar continuïtat i reestructurar l'obra d'Alcover, que va finalitzar amb els vint-i-quatre volums actuals. Moll, doncs, tanca el cicle d'Alcover, el qual s'estén des de I88o fins a I930 - període que podríem anomenar l'època d'or del folklore català-, cinquanta anys que Alcover es passarà recollint, reelaborant i publicant rondaies mallorquines.

Al segon apartat d'aquest article, Guiscafrè parla de la difusió que va tenir l'Aplec de les rondalles mallorquines en altres llengües. Posa de relleu que, després d'una primera traducció al castellà, publicada el I9I3 dins del volum Cuentos de la Isla Dorada, a partir dels anys I930 apareixen ja traduccions en anglès - la llengua en què se n'ha publicat més traduccions-, en francès (I937) i en alemany (I945). Ja el I96I es publica en aquesta llengua un recull de rondalles en català de diversos autors, i es fa una proposta de classificació segons Aarne i Thompson. Fins al

\footnotetext{
3 La importància d'Aguiló en el panorama de la rondallística catalana i internacional pel que fa al volum i, sobretot, al caràcter precoç de la seva obra és tractat per Guiscafrè a la seva obra El rondallari Aguiló. Transcripció, catalogació i estudi introductori. Barcelona: Publicacions de l'Abadia de Montserrat, 2008.

4 Aquesta proliferació de rondalles en publicacions periòdiques ha estat explicada per la professora de la URV Mònica Sales de la Cruz a Quan les revistes conten rondalles. Barcelona: Publicacions de l'Abadia de Montserrat, 2016.
} 
moment de publicar aquest llibret hi ha traduccions parcials de l'Aplec també al japonès, al romanès, al rus i al txec.

El gruix de l'article, tanmateix, és al final: vuitanta-dues pàgines amb una detallada bibliografia - per bé que, segons l'autor, no del tot exhaustiva- de totes les rondalles publicades per Antoni M. Alcover, organitzada a partir del títol assignat a cada rondalla, i en què es poden localitzar les revistes i volums on van veure la llum, acompanyades de la data, així com el títol de les traduccions d'aquelles que en van tenir.

Els articles «Antoni M. Alcover, l'instituïdor del cànon rondallístic» i «Antoni M. Alcover, el narrador generós» tenen bastants punts de contacte. Ambdós se centren a explicar el programa fixat pel mateix Antoni M. Alcover i la seva manera de treballar. El caràcter de la seva obra, en definitiva. També el seu èxit en el camp de la divulgació, en contrast amb el que s'esdevingué amb el primer compilador de literatura oral en llengua catalana, Marià Aguiló: «[Aguiló] li confessava [a Alcover] que havia estat precisament la dificultat de trobar un model de llengua literària adequat el que l'havia impedit de publicar les rondalles que ell havia recollit. I hi afegia que l'única satisfacció de la seva vellesa era veure que tot el que havia intentat fer en favor de la llengua catalana es feia o es faria millor del que ell n'havia estat capaç».

Guiscafrè ressalta que Alcover és més rondallaire que rondallista, perquè no esmerça gaires esforços a «reflexionar sobre la naturalesa, l'origen, la difusió o la funció d'aquelles versions [de les rondalles recollides]». De fet, diu, «tota la doctrina rondallística, tota la teorització sobre el conte oral, d'Alcover, és continguda en tres textos: les dues versions del pròleg a la primera edició del primer volum de l'Aplec de Rondaies Mallorquines, publicades el I896 i el I9I5, i "Com he fet mon Aplec de Rondaies Mallorquines", que no és altra cosa que la versió ampliada i refosa dels dos pròlegs esmentats». L'autor ens descriu Alcover com un individu que mai no va voler ser un outsider, un folklorista que s'ho mira tot des de l'exterior, sinó com un home que es considerava a si mateix com a part del receptor de la seva obra, que no és cap altre que el poble mallorquí. El mateix Alcover deixa clar que no perseguia cap fi tècnic ni científic, sinó amb una finalitat patriòtica; el seu aplec era destinat a la gent comuna de Mallorca $i$ «a la propaganda de la santa causa que du per lema Déu i Pàtria». Un capteniment que l'allunyen de personatges erudits o més lligats a l'acadèmia, com Milà i Fontanals o els germans Grimm de la primera època.

Alcover va explicar a «Com he fet mon Aplec de Rondaies Mallorquines» que tenia dos objectius: inventariar en forma de col-lecció de rondalles el patrimoni narratiu oral de Mallorca i inventariar en forma de diccionari el patrimoni lingüístic català. Guiscafrè s'aplica en el primer d'aquests dos articles a explicar les diferències entre rondalla autèntica (un acte social de caràcter oral, únic, efímer i irrepetible), la metarondalla i rondalla d'autor («textos que resulten d'un procés conscient d'aplicació de tècniques de representació literària a una descripció d'un acte narratiu obtingut prèviament, o a diverses»). Aquesta digressió, que es desenvolupa al llarg de tres pàgines, així com l'explicació de què és un «tipus» de rondalla segons allò que va establir Antti Aarne, no és més que un preàmbul per explicar què va fer i què no va fer Antoni M. Alcover. Guiscafrè ho deixa clar: «Alcover no va constituir un aplec de rondalles en sentit estricte, sinó un aplec de rondalles d'autor», una característica que atribueix al gruix de la rondallística 
catalana. Estem parlant, per tant, de rondalles reelaborades a partir de versions diferents, anotades en llibretes de camp o simplement extretes de la memòria de l'autor, que coneix prou el patrimoni narratiu propi per fer-ho. «El resultat és sempre una homogeneïtzació estilística i lingüística dels corpus rondallístics que elimina les diferències que esperaríem trobar en un recull de descripcions d'actes narratius deguts a narradors diferents».

Guiscafrè fa una caracterització de l'estil d'Alcover en ambdós articles (més detallat en «Antoni M. Alcover, l'instituïdor del cànon rondallístic»), que ens ajuda a entendre els criteris que va aplicar a la seva tasca recreativa:

a) Expansió.

b) Equilibri entre l'estil abstracte, propi de la rondalla — sobretot de la meravellosa- i el realisme, propi de la novel.la.

c) Carnavalitat, «realisme grotesc», un concepte desenvolupat per Bakhtin i que aquest autor situa en èpoques anteriors al Renaixement.

d) Aprofitament savi del llenguatge, i en concret del dialecte mallorquí. «En definitiva, la llengua amb què estan redactats els textos de l'Aplec correspon a un model de llengua que no feia servir ningú a Mallorca però que tothom sens dubte reconeixia com a propi i en el qual es reconeixia». Quelcom molt semblant a allò que van fer els germans Grimm per a la llengua alemanya.

Guiscafrè, de fet, lloa la importància «(re)creativa» de l'obra d'Alcover, que sempre va deixar molt clar que feia l'obra per «al poble mallorquí», i no per als folkloristes. «Si de cada rondalla s'havia de transcriure i publicar la versió del contador, ¿qui resistiria la lectura?». Guiscafrè fa una interessant aportació de detall relativa a aquests contadors: qui foren els informants d'Alcover? «La seva activitat recol-lectora de les versions orals pràcticament es va limitar als seus familiars i a la gent amb què es va relacionar de manera més assídua com a mínim durant la infantesa i l'adolescència, és a dir, els treballadors de l'explotació agrícola en què havia nascut, que eren tots naturals d'alguns pobles situats al llevant de Mallorca.» En total, Guiscafrè ascendeix a dues-centes vint-i-vuit el nombre de persones que varen contribuir amb alguna versió a la constitució de l'Aplec, en graus diferents d'aportació de materials, des de simples «informants» fins a «narradors» com a tals.

Guiscafrè situa aquesta dinàmica alcoveriana dins del programa de construcció d'una literatura en llengua pròpia que ja Jaume Collell proposa dins «Cantem massa i parlem poc» (I868), i en el qual les «poètiques tradicions», els «fets llegendaris» $\mathbf{i}$ «un sens fi d'encantadores rondalles» hi ocupen un lloc al mateix nivell que els altres. El resultat d'aquesta manera de treballar, recreativa i literària al cap i a la fi, va resultar un èxit segons Guiscafrè, que compara el procés de «reoralització» que va suposar l'Aplec amb el del resultant de la publicació de les obres dels germans Grimm. Destaca també que l'Aplec influeix en els rondallaires posteriors en tres aspectes: I) recullen rondalles «inèdites»; 2) renuncien explícitament a donar tractament científic a les versions orals, i 3) manifesten la voluntat explícita d'emular el llenguatge i l'estil d'Alcover.

Guiscafrè acaba posant de relleu que la influència i la força divulgadora de l'obra d'Alcover no s'esgota en allò que va escriure, sinó que a principis dels anys seixanta va fer el salt a la ràdio, o sigui, per dir-ho en termes d'Ong, a l'oralitat secundària. 
Es jaquet d'en Jordi des Racó és una obra, en definitiva, que permet entendre la dimensió de l'obra d'Antoni M. Alcover. La seva dimensió quantitativa, amb tot luxe de detalls sobre revistes, volums compilatoris i traduccions de les rondalles recollides per Alcover. I la seva dimensió qualitativa. En aquest sentit, el recull d'articles deixa clara, d'una banda, la gran influència que va tenir en la reoralització del patrimoni narratiu de l'illa de Mallorca dins de la mateixa illa; de l'altra, el que va suposar d'institucionalització d'un cànon, d'una manera de fer que van seguir la majoria de recol-lectors de rondalles en llengua catalana, caracteritzat per la recreació literària de les rondalles sense perdre - o almenys intentant-hola frescor de la llengua parlada. 